\title{
Experimental and theoretical researches of high-speed interaction of thin obstacles with a metal fragment
}

\author{
Svetlana Afanasyeva ${ }^{1}$, Viktor Burkin ${ }^{1}$, Aleksey Dyachkovsky ${ }^{1}$, Alexandr Ishchenko $^{1}$, \\ Konstantin Rogaev ${ }^{1}$, Anton Sammel ${ }^{1, *}$, Aleksey Sidorov ${ }^{1}$, Anatoly Skosyrsky ${ }^{1}$, Evgeny \\ Stepanov $^{1}$, and Andrey Chupashev ${ }^{1}$ \\ ${ }^{1}$ National Research Tomsk State University, 36, Lenin Ave., Tomsk, 634050 Russia
}

\begin{abstract}
The development of lightweight protective structures of increased ballistic resistance is not an easy task, since often there are conflicting requirements in terms of cost, weight, thickness, materials availability, processability, etc. To assess the effectiveness of protective structures one should use methods that allow to research the obstacles destruction when collided with high-speed particles. The paper is devoted to the actual problem of studying the ballistic stability of thin barriers made of various protective materials (steel, titanium alloy, ceramics, metal ceramics) when interacting with a metal fragment simulator - a spherical steel drummer - in the range of interaction speeds of about $2500 \mathrm{~m} / \mathrm{s}$. An experimental technique has been developed to study the most important indicators: the depth of a crater in an obstacle, a fragment's velocity drop when interacting with protection, the obstacle's and splinter's fragments scattering in overgraded space. Mathematical modeling was carried out within the framework of continuum mechanics, which adequately describes the interaction process of the drummer and the obstacle under various impact conditions.
\end{abstract}

\section{Introduction}

The development of lightweight protective structures of increased ballistic resistance is not an easy task, since often there are conflicting requirements in terms of cost, weight, thickness, materials availability, processability, etc. In addition, the design must take into account the spectra of threats, which include, in particular, the defeat of obstacles in collisions with high-speed fragments. Recently, there are many researches conducted in the field of the protective barrier's ballistic resistance increase against high-speed collisions with metal fragments.

In high-speed collisions, single-layer protective ceramic barriers are fragile and unreliable. High-hard ceramics contain a large number of strain concentrators (grain boundaries, cracks, pores, etc.) even in the area of elastic deformation of the material. Microdamages in such materials may appear under compression under the influence of

\footnotetext{
${ }^{*}$ Corresponding author: anton_sammel@mail.ru
} 
deviatoric strains. With an increase in the intensity of the load pulse, the degree of microdestruction in the compression phase increases sharply, which subsequently leads to a drop in tensile strength [1]. The literature data analysis [2-7] shows that increasing the strength of metallic materials has not exhausted its capabilities. As a promising solution for protective systems, the use of multilayer structures is noted, the individual layers of which are made from metal-ceramic materials in combination with durable metal layers, and in general, they are characterized by enhanced performance characteristics. One of the progressive methods of obtaining such structures is self-propagating high-temperature synthesis (SHS) with simultaneous pressure application to a layered preform containing an exothermic powder mixture [8]. The developed SHS-technologies make it possible to quickly and effectively solve the problem of creating materials of a new generation [9].

The purpose of this article is to develop a methodology for conducting ballistic tests of thin barriers of various protective materials during high-speed collisions with a metal fragment and to study the behavior of protective barriers in the range of impact speeds of $2500 \mathrm{~m} / \mathrm{s}$.

A series of experiments in a wide range of speeds was carried out on an experimental ballistic complex [10]. Numerical simulation was carried out in the framework of the mathematical model [11]. The spherical pores growth model is used as a materials destruction model [12]. The software package was used for calculation [13].

\section{Experimental part}

In order to determine the ballistic stability of thin barriers made of various protective materials, ballistic tests of plates made of specified materials were carried out in a highspeed collision with a high-speed fragment. A series of experiments was carried out on a ballistic stand equipped with a $23 \mathrm{~mm}$ caliber smooth-bore ballistic unit, fig. one.

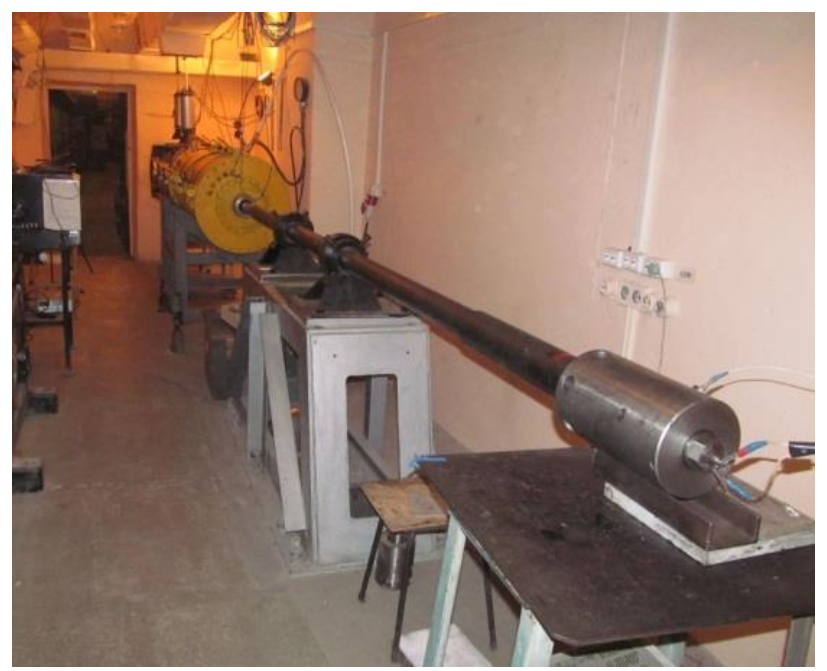

Fig 1. Ballistic stand.

A steel spherical drummer was used as a high-speed splinter simulator, fig. 2. The drummer is made of bearing steel SHH15 with mass $\mathrm{m}=2.18 \mathrm{~g}$ and diameter $\mathrm{d}=8.1 \mathrm{~mm}$. To determine the armor resistance of the tested materials samples, the two series of experiments were carried out: in the first series of experiments the sample is located directly on the barrier - "witness", in the second series the sample is at some distance L = 
$215 \mathrm{~mm}$ from the barrier - "witness". In all cases, the depth of the crater h in the "witness" was measured as the main armor resistance indicator. A massive disk made of D16T aluminum alloy with a density of $\rho_{\text {wit }}=2.78 \mathrm{~g} / \mathrm{cm}^{3}$ was used as a barrier - "witness".

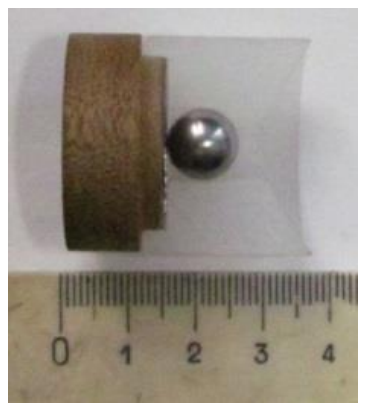

Fig 2. The type of steel spherical drummer in the master

The following samples of materials were used for tests: corundum ceramics No. 1 $\mathrm{Al}_{2} \mathrm{O}_{3}$, two-layer cermet materials No. $2\left(\mathrm{TiB}_{2}+\mathrm{NiTi}\right)+\mathrm{Ti}$ [9], titanium alloy No. 3 VT1-0 and plate of steel grade St3 - No. $4 \mathrm{St} 3$. The sample $\left(\mathrm{TiB}_{2}+\mathrm{NiTi}\right)+\mathrm{Ti}$ consists of two layers: the front layer $4.5 \mathrm{~mm}$ thick is cermet $\left(\mathrm{TiB}_{2}+\mathrm{NiTi}\right)$ with a density of $4.92 \mathrm{~g} / \mathrm{cm}^{3}$, the back layer $3 \mathrm{~mm}$ thick is an alloy of titanium VT1-0 with a density of $4.32 \mathrm{~g} / \mathrm{cm}^{3}$. The average density of the sample $\left(\mathrm{TiB}_{2}+\mathrm{NiTi}\right)+\mathrm{Ti}$ is $4.68 \mathrm{~g} / \mathrm{cm}^{3}$. Fig. 3 demonstrates the photographs of the tested materials samples.

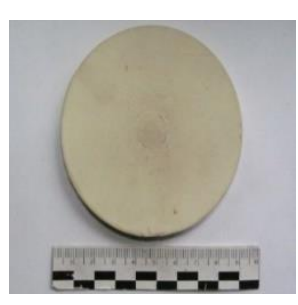

No. $1 \mathrm{Al}_{2} \mathrm{O}_{3}$

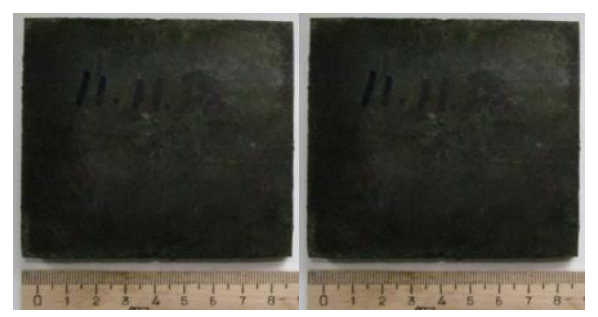

No. $2\left(\mathrm{TiB}_{2}+\mathrm{NiTi}\right)+\mathrm{Ti}$

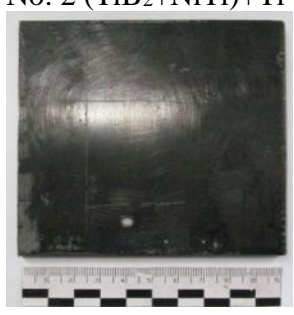

No. $4 \mathrm{St} 3$

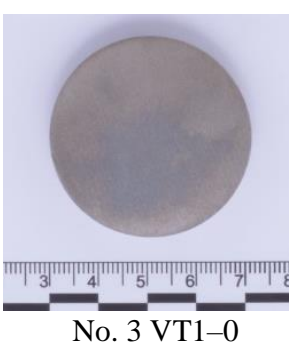

No. 3 VT1-0

Fig. 3. The samples of tested materials

Table 1 and fig. 4, 5 show the results of the first series of experiments at an impact velocity V0 of about $2500 \mathrm{~m} / \mathrm{s}$. After a collision with a steel spherical drummer, sample No. $1 \mathrm{Al}_{2} \mathrm{O}_{3}$ collapsed completely into a fine crumb. In a collision with sample No. $2\left(\mathrm{TiB}_{2}+\right.$ $\mathrm{NiTi})+\mathrm{Ti}$, the drummer breaks through both layers. The front layer is partially destroyed, a through hole is formed in the back layer. The drummer also breaks through the samples No. 3 VT1-0 and No. 4 St3, forming a through hole in them. After each experiment in the barrier - "witness" there remains a crater, fig. 5. All the measurement results of the craters in the barrier - "witness" are displayed in table 1. 
Judging by the results of the first series of experiments, sample No. $1 \mathrm{Al}_{2} \mathrm{O}_{3}$ has the lowest armor resistance: first, it completely collapsed after the impact, and, second, left the crater of the greatest depth in the barrier-"witness". A armor resistance comparison of samples No.2 $\left(\mathrm{TiB}_{2}+\mathrm{NiTi}\right)+\mathrm{Ti}$ and No.3 VT1-0 with close surface density shows similar results, however, the sample No.3 has a high impact velocity, which makes correct comparison difficult. Sample No.4 St3 showed armor resistance close to sample No.1 $\mathrm{Al}_{2} \mathrm{O}_{3}$.

Table 1. The results of the first series of ballistic tests

\begin{tabular}{|c|c|c|c|c|c|}
\hline Sample & $\begin{array}{c}\text { Sample } \\
\text { thickness } h_{\text {sam }}, \\
\mathrm{mm}\end{array}$ & $\begin{array}{c}\text { Sample } \\
\text { density, } \rho_{\text {sam }}, \\
\mathrm{g} / \mathrm{cm}^{3}\end{array}$ & $\begin{array}{c}\text { Surface } \\
\text { density, } \rho_{\text {sam }}, \\
\mathrm{g} / \mathrm{cm}^{2}\end{array}$ & $\begin{array}{c}\text { Impact } \\
\text { velocity } V_{0}, \\
\mathrm{~m} / \mathrm{s}\end{array}$ & $\begin{array}{c}\text { Crater } \\
\text { depth h, } \\
\mathrm{mm}\end{array}$ \\
\hline No. 1 & 8.00 & 3.20 & 2.56 & 2515 & 9.97 \\
\hline No. 2 & 7.42 & 4.68 & 3.47 & 2481 & 9.32 \\
\hline No. 3 & 7.81 & 4.51 & 3.52 & 2638 & 9.16 \\
\hline No. 4 & 4.80 & 7.85 & 3.77 & 2413 & 9.93 \\
\hline
\end{tabular}

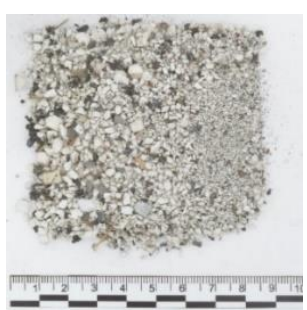

No. 1

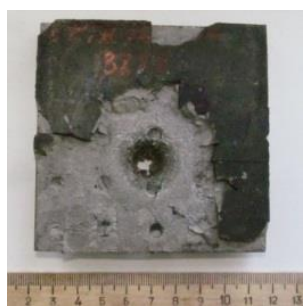

No. 2

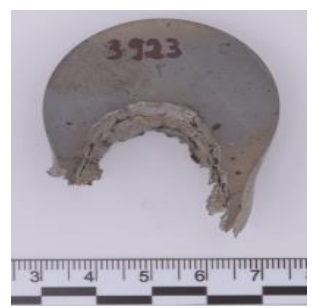

No. 3

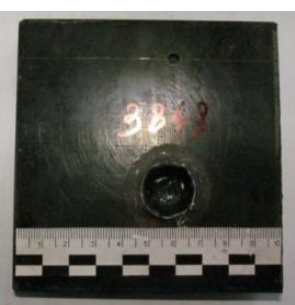

No. 4

Fig 4. Samples after impact in the first series of experiments

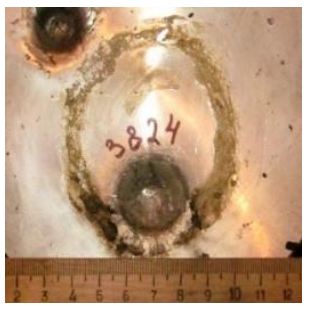

No. 1

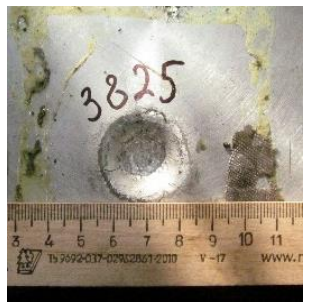

No. 2

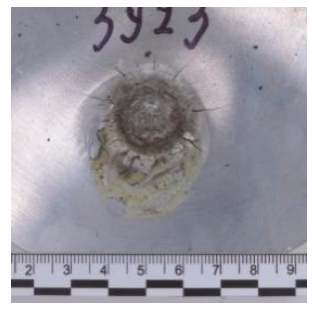

No. 3

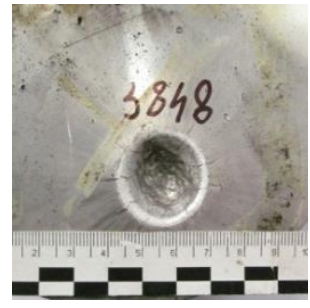

No. 4

Fig 5. Crater in the barrier-"witness" after impact in the first series of experiments

Below are the results of experiments with the separation of the tested samples and barrier - "witness" table 2 and fig. 6 - 8 . There is also the value of the velocity drop $\Delta V=1$ - $\left(V_{0}-V_{\mathrm{k}}\right) / V_{0}$. High-speed video was used to measure the speed of the drummer before and after the collision. Fig. 6 demonstrates the interaction of the drummer with sample No. 1 $\mathrm{Al}_{2} \mathrm{O}_{3}$ in a time interval of $1.29 \mathrm{~ms}$ (movement of the drummer from right to left). After the collision, a cloud of fragments with a leading fragment of a drummer expanding in a certain solid angle $\varphi$ is observed.

Like in the first series of experiment, after interaction with the drummer Sample No. 1 $\mathrm{Al}_{2} \mathrm{O}_{3}$ crumbled into small fragments. In the barrier-"witness", a single crater of the greatest depth was formed in this series of experiments. The drummer breaks through the two-layer plate No. $2\left(\mathrm{TiB}_{2}+\mathrm{NiTi}\right)+\mathrm{Ti}$. The front layer is destroyed, the back titanium layer is broken through. The drummer, after interacting with this plate, shatters into small fragments. There are a lot of small craters from fragments of the drummer and the barrier in 
the barrier-"witness". Table 2 shows the depth of the deepest crater, formed by the leading fragment of the drummer. The result of the collision with samples No. 3 VT1-0 and No. 4 $\mathrm{St} 3$ is similar to the previous case. In this series of experiments, sample No. $2\left(\mathrm{TiB}_{2}+\mathrm{NiTi}\right)$ $+\mathrm{Ti}$ has the smallest crater formed by the leading fragment and the largest angle of the scattering fragments.

Table 2. The results of the second series of ballistic tests

\begin{tabular}{|c|c|c|c|c|c|c|c|}
\hline Sample & $\begin{array}{c}\text { Sample } \\
\text { thickness } \\
\mathrm{h}_{\text {sam, }} \mathrm{mm}\end{array}$ & $\begin{array}{c}\text { Sample } \\
\text { density } \\
\rho_{\text {sam, }} \\
\mathrm{g} / \mathrm{cm}^{3}\end{array}$ & $\begin{array}{c}\text { Impact } \\
\text { velocity } \\
V_{0}, \mathrm{~m} / \mathrm{s}\end{array}$ & $\begin{array}{c}\text { After- } \\
\text { impact } \\
\text { velocity } \\
V_{\mathrm{k}}, \mathrm{m} / \mathrm{s}\end{array}$ & $\begin{array}{c}\text { Velocity } \\
\text { drop } \\
\Delta V, \%\end{array}$ & $\begin{array}{c}\text { The depth of } \\
\text { the crater } \\
\text { formed by } \\
\text { the leading } \\
\text { fragment } h, \\
\mathrm{~mm}\end{array}$ & $\begin{array}{c}\text { Solid } \\
\text { angle of } \\
\text { shattering } \\
\text { fragments } \\
\varphi, \text { degree }\end{array}$ \\
\hline No. 1 & 8.00 & 3.14 & 2357 & 1523 & 64 & 8.69 & - \\
\hline No. 2 & 7.50 & 4.68 & 2395 & 1405 & 59 & 5.46 & 35.4 \\
\hline No. 3 & 9.00 & 4.51 & 2433 & 1204 & 49 & 7.33 & 31.81 \\
\hline No. 4 & 4.80 & 7.85 & 2413 & 1403 & 58 & 6.45 & 24.91 \\
\hline
\end{tabular}

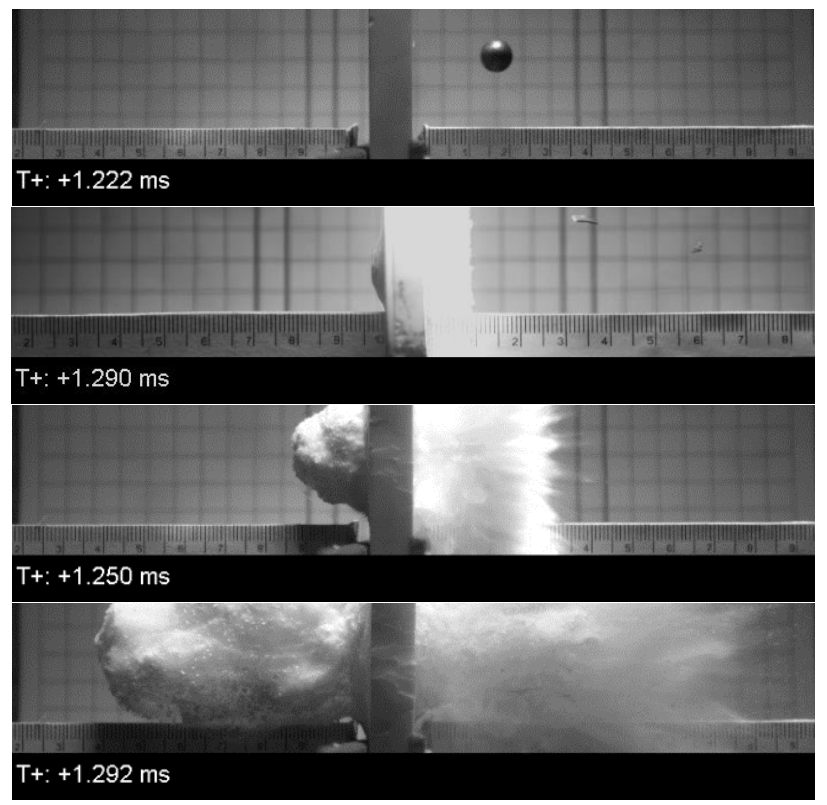

Fig 6. Photographic record of the sample No. $1 \mathrm{Al}_{2} \mathrm{O}_{3}$ break through

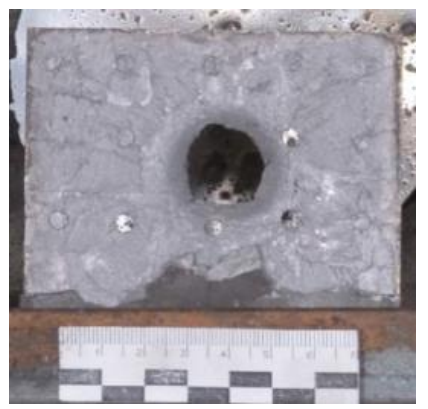

No. 2

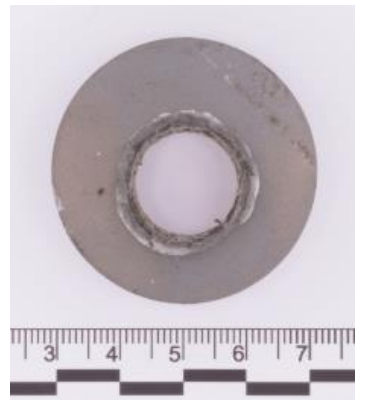

No. 3

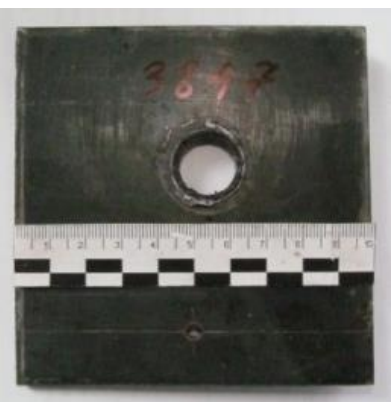

No. 4

Fig 7. Samples after impact in the second series of experiments 


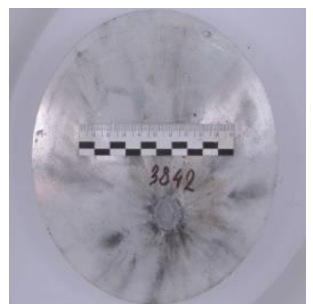

No. 1

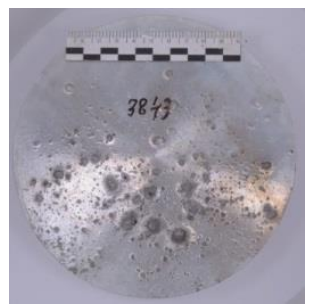

No. 2

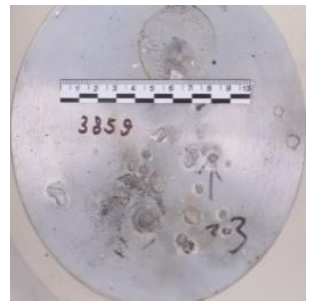

No. 3

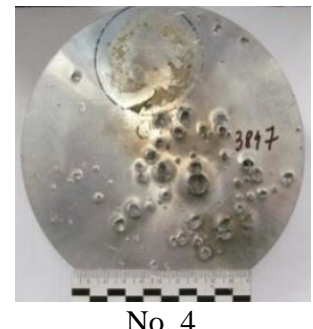

No. 4

Fig 8. Craters in the barrier-"witness" after drummer's impact on the sample in the second series of experiments

For the armor resistance comparison of the tested materials samples the equivalent depth of the crater in the barrier-"witness" after the spherical drummer impact was determined by the results of the experiments with the use of the next formula:

$$
L_{\text {sam }}^{e q}=h+\frac{\rho_{\text {sam }} * \mathrm{~h}_{\text {sam }}}{\rho_{\text {wit }}}
$$

the effective thickness at which the drummer does not pierce the tested sample:

$$
h_{\text {sam }}^{e f f}=h_{\text {sam }}+\frac{\rho_{w i t} * h}{\rho_{\text {sam }}}
$$

and the surface density $\rho_{\text {Ssam }}$ of each tested plate at the estimated effective thickness $h_{\text {sam }}^{\text {eff }}$. All calculations are given in table 3 . The results are calculated for two cases when the sample is on the barrier and at a distance from it.

If sample No. $1 \mathrm{Al}_{2} \mathrm{O}_{3}$ is not taken into consideration due to its complete destruction after the collision, then from the analysis of the estimates from the results of the second series of experiments, we can state the advantages of sample No. $2\left(\mathrm{TiB}_{2}+\mathrm{NiTi}\right)+\mathrm{Ti}$.

Table 3. Estimates.

\begin{tabular}{|c|c|c|c|c|c|c|}
\hline \multirow{2}{*}{$\begin{array}{c}\text { Sample } \\
\text { material }\end{array}$} & \multicolumn{2}{|c|}{ Samples on the barrier-"witness" } & \multicolumn{3}{|c|}{ Samples at a distance from the barrier- } \\
\cline { 2 - 7 } & $L_{\text {sam }}^{\text {eq }}, \mathrm{mm}$ & $h_{\text {sam }}^{\text {eff }}, \mathrm{mm}$ & $\begin{array}{l}\rho \text { Ssam, } \\
\mathrm{g} / \mathrm{cm}^{2}\end{array}$ & $L_{\text {sam }}^{\text {eq }}, \mathrm{mm}$ & $h_{\text {sam }}^{\text {eff }}, \mathrm{mm}$ & $\begin{array}{l}\rho_{\text {ssam, }} \\
\mathrm{g} / \mathrm{cm}^{2}\end{array}$ \\
\hline No. 1 & 19.18 & 16.7 & 5.33 & 17.73 & 15.7 & 4.93 \\
\hline No. 2 & 21.81 & 12.95 & 6.35 & 18.08 & 10.7 & 5.32 \\
\hline No. 3 & 21.72 & 13.5 & 6.04 & 21.93 & 13.5 & 6.10 \\
\hline No. 4 & 23.48 & 8.3 & 6.51 & 20.0 & 8.1 & 6.35 \\
\hline
\end{tabular}

\section{Math modeling}

Next, we consider the mathematical modeling of the high-speed interaction of a steel spherical drummer with a target of $\mathrm{Al}_{2} \mathrm{O}_{3}$. Numerical simulation was carried out with initial data repeating conditions from the first series of experiments, when the tested obstacle is located directly on the barrier — "witness" at $V 0=2515 \mathrm{~m} / \mathrm{s}$ (Fig. 9 a), and the second series of experiments - the interaction of a drummer with a single obstacle without taking into account the barrier - "witness" at $V 0=2357 \mathrm{~m} / \mathrm{s}$ (Fig. 9 b). 


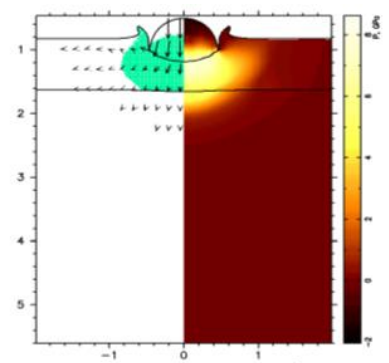

$t=1.9 \mathrm{mcs}, u_{\max }=2319 \mathrm{~m} / \mathrm{s}, u_{\mathrm{sp}}=1973 \mathrm{~m} / \mathrm{s}$

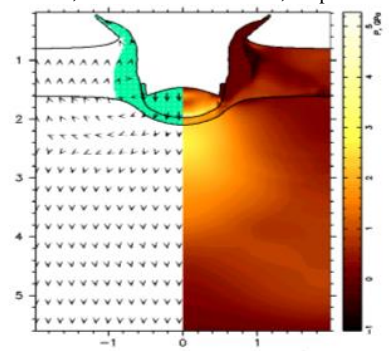

$t=7.9 \mathrm{mcs}, u_{\max }=995 \mathrm{~m} / \mathrm{s}, u_{\mathrm{sp}}=966 \mathrm{~m} / \mathrm{s}$

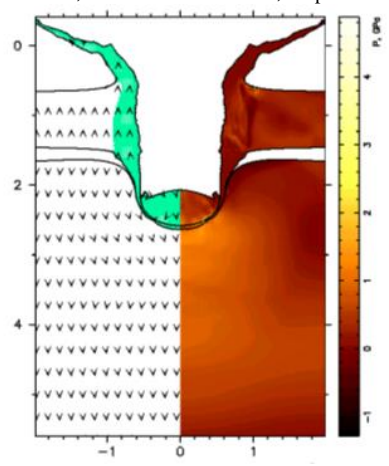

$t=22 \mathrm{mcs}, u_{\max }=873 \mathrm{~m} / \mathrm{s}, u_{\mathrm{sp}}=11 \mathrm{~m} / \mathrm{s}$

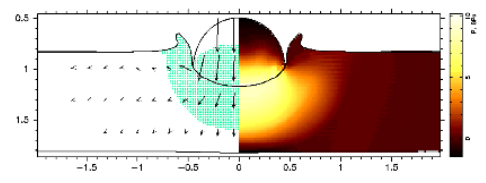

$t=2 \mathrm{mcs}, u_{\max }=2238 \mathrm{~m} / \mathrm{s}, u_{\mathrm{sp}}=1912 \mathrm{~m} / \mathrm{s}$

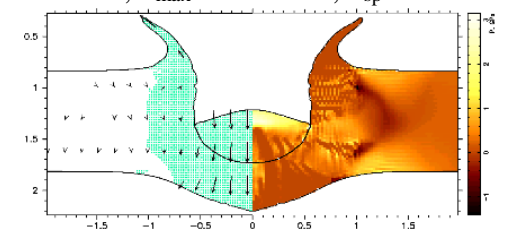

$t=6 \mathrm{mcs}, u_{\max }=1352 \mathrm{~m} / \mathrm{s}, u_{\mathrm{sp}}=1193 \mathrm{~m} / \mathrm{s}$

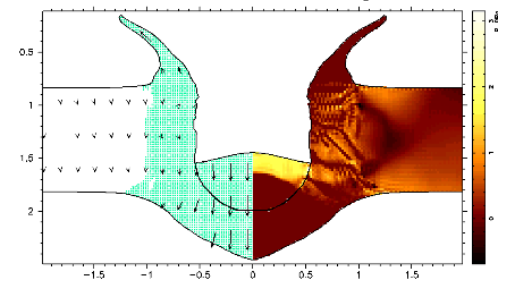

$t=8 \mathrm{mcs}, u_{\max }=1319 \mathrm{~m} / \mathrm{s}, u_{\mathrm{sp}}=1091 \mathrm{~m} / \mathrm{s}$

Fig 9. Chronogram of the interaction process of a steel spherical drummer with a $\mathrm{Al}_{2} \mathrm{O}_{3}$ barrier

The results are presented in the form of a velocity field with respect to the maximum velocity $u_{\max }$ (left) and pressure field (right) in a cylindrical coordinate system $x, z,(\mathrm{~cm})$ at various points in time $t$ of the interaction between the drummer and the obstacle. It also shows the values of the velocity of the drummer's center of mass $u_{\max }$.

In the first case, the calculation is stopped when the drummer in the barrier is almost completely stopped. The estimated depth of the crater is $9.8 \mathrm{~mm}$.

In the second case, the calculation is stopped when the speed of the drummer behind the obstacle ceases to change with time. At the same time, the drummer's speed is $u_{\mathrm{cm}}=1091$ $\mathrm{m} / \mathrm{s}$ and it ensures complete penetration of the obstacle. Judging by the results of the experiment (Fig. 6), the splitting of the barrier into small fragments occurs in the time interval of $1.29 \mathrm{~ms}$, which is later than the interval considered in the calculation.

In the considered period of time there was a destruction of the drummer and the destruction of the barrier (marked in green), which, judging by the velocity vector, will continue to expand. Local macroscopic ceramics destruction occurs during compression as a result of plastic wicking of pores. The drummer destruction occurs by a shear mechanism.

The accordance between the calculation and the experiment on the crater depth is $2.6 \%$, and on the residual speed of the drummer $-0.8 \%$. 


\section{Conclusion}

The method of researching the thin protective obstacle's armor resistance against a highspeed metal fragment, presented in this article, showed performance in the range of impact speeds of about $2500 \mathrm{~m} / \mathrm{s}$ and the possibility of conducting a comparative analysis for the most important indicators: the crater depth in the barrier-"witness", the fragment's velocity drop on the impact with protection, the barrier's and the drummer's fragments scatter.

Among the studied samples of protective materials, a two-layer cermet material $\left(\mathrm{TiB}_{2}+\right.$ $\mathrm{NiTi})+\mathrm{Ti}$ is distinguished by the highest armor resistance in the speed range of about $2500 \mathrm{~m} / \mathrm{s}$.

Mathematical modeling with the help of the chosen model of continuum mechanics adequately describes the interaction process between the drummer and the barrier under various impact conditions.

In this paper, we used the results obtained in the course of project implementation No. 8.2.09.2018 of the TSU competitiveness improvement program.

\section{References}

1. G.I. Kanel, S.V. Razorenov, A.V. Utkin, V.E. Fortov, Shock wave phenomena in condensed matter. 408, (Moscow, Janus-K, 1996) (in Russian)

2. E.F. Dudarev, G.P. Grabovetskaya, Yu.R. Kolobov, G.P. Bakach, O.A. Kashin, Yu.T. Zhu, Metals, 1, 87-95 (2004) (in Russian)

3. E.F. Dudarev, G.P. Bakach, G.P. Grabovetskaya, Yu.R. Kolobov, O.A. Kashin, Yu.T. Zhu. Russian metallurgy, (Metals), 1, 75-82 (2004) (in Russian)

4. A.N. Ishchenko, S.A. Afanasyeva, V.V. Burkin, E.F. Dudarev, K.S. Rogaev, A.N. Tabachenko, M.V. Khabibullin, Space Research. 54, 6, 479-485 (2016)

5. A.N. Ishchenko, S.A. Afanasyeva, V.V. Burkin, E.F. Dudarev, K.S. Rogaev, A.N. Tabachenko, and M.V. Khabibullin, Cosmic Research, 54, 6, 438-444 (2016)

6. O.V. Ponomarev, M.Yu. Popov, E.V. Tyukalova, V.D. Blank, Letters to TPJ, 42, 21 (2016)

7. V.I. Betekhtin, J. Dvorak, A.G. Kadomtsev, B.K. Kardashev, M.V. Narykova, G.K. Raab, V. Sklenicka, S.N. Faizova, Letters to TPJ, 41, 2, 58-64 (2015)

8. A.N. Ishchenko, A.N. Tabachenko, S.A. Afanasyeva, N.N. Belov, V.V. Burkin, L.S. Martsunova, K.S. Rogaev, N.T. Yugov, Izvestia vuzov. Physics, 58, 9, 131-135 (2015) (in Russian)

9. V.V. Burkin, A.N. Tabachenko, S.A. Afanasyeva, A.N. Ishchenko, A.Yu. Sammel, A.B. Skosyrsky, A.V. Chupashev, Letters to TPJ, 44, 8, 63-69 (2018). DOI: 10.21883 / PJTF.2018.08.45968.16945.

10. V.A. Burakov, V.V. Burkin, A.N. Ishchenko et al. Patent for invention № 2591132 dated June 20, 2016

11. N.N. Belov, V.N. Demidov, L.V. Efremova, A.V. Zhukov, A.P. Nikolaev, V.G. Simonenko, V.G. Trushkov, M.V. Habibullin, I.E. Shipovskiy, V.B. Shutalev, Izvestia vuzov. Physics, 8, 5-48 (1992) (in Russian)

12. M.V. Khabibullin, S.A. Afanasyeva, The calculation of phenomena occurring in condensed matter as a result of intense impulse effects in axisymmetric formulation. Federal Service for Intellectual Property. Certificate of state registration of computer programs. (No. 2012617301. Moscow., 2012) (in Russian)

13. N.N. Belov, A.I. Korneev, A.P. Nikolaev, Numerical analysis of plates failure under the influence of impulse loads, PMTF, 3, 132-136 (1985) 